\title{
Reflexões sobre tecnologia e educação em tempo de pandemia
}

\author{
https://doi.org/10.21814/uminho.ed.24.9
}

\section{António José Osório}

António José Osório (ORCID: 0000-0002-9931-1962) é Professor Associado com agregação do Instituto de Educação da Universidade do Minho e investigador do Centro de Investigação em Educação, no grupo de Tecnologias, Multiliteracias e Curriculum. É Diretor do Mestrado em Ensino de Informática e coordenador da especialidade de Tecnologia Educativa do Doutoramento em Ciências da Educação. Possui experiência docente na formação inicial e contínua de educadores e professores. 


\section{INTRODUÇÃO}

A reflexão, que aqui se apresenta, sobre a sua função na educação, é feita na assunção de que a tecnologia faz sentido se ajudar alguém a aprender (Spector, 2020). Dispomos de ampla evidência sobre a possível mais-valia das Tecnologias de Informação e Comunicação (TIC) na educação, assim como observámos abundantemente como a Internet, os computadores e os telemóveis nos ajudam a viver a pandemia. E sabendo que a tecnologia, posta à prova, respondeu às dúvidas dos mais céticos (Osório, 2020), também devemos estar cientes da necessidade de constantemente refletirmos sobre como melhor somos capazes de a controlar com intencionalidade. A lógica deste argumento é que um melhor conhecimento sobre a intervenção da tecnologia na educação, concorre para melhores decisões na vida em geral e, em particular, na atividade dos diversos intervenientes no processo educativo, designadamente alunos, educadores e professores, famílias e decisores.

A perceção de que as instituiçôes educativas, que tivessem anteriormente integrado práticas intencionais de uso das tecnologias, iriam conseguir lidar melhor com a situação pandémica e reagir mais adequadamente à impossibilidade de as pessoas se poderem encontrar fisicamente nas suas escolas para terem aulas convencionais, justificava o receio de que, quem nunca experimentou nada que implicasse soluçóes online ou a distância, começasse a fazê-lo tranquilamente, de repente, para fazer face à emergência, como se a aprendizagem remota, ou a distância, fosse, apenas, uma alternativa que se usa como um remedeio. Para usar uma analogia sugerida por Rutter (2020), passar as aulas do regime dito presencial para um ensino e aprendizagem a distância foi, menos, o acionar de um interruptor e, mais, a sua própria construção, recorrendo, exclusivamente, aos recursos disponíveis num contexto precário.

Ficámos perante uma situação totalmente nova, à qual tivemos de reagir como nunca antes, tendo todos de o fazer de modo responsável e colaborativo. Ficámos diante de uma ocorrência a pedir conhecimento que não existe, a ter de percorrer caminho que não conhecemos e que temos de ir descobrindo, recolhendo dados e, ao caminhar, esboçando os mapas do trajeto e concebendo as ferramentas e os procedimentos para nos podermos orientar e manter vivos e em ação. Atrevendo uma comparação, possivelmente exagerada, dadas a distância temporal de meio milénio e a diferente 
conjuntura tecnológica, trata-se de uma vivência que faz lembrar o que sabemos sobre a época dos descobrimentos.

A reflexão é feita em três etapas: a inicial, em que procuramos compreender características da situação complexa em análise; uma etapa intermédia para inventariar aprendizagens em curso; finalmente, perspetivamos algumas orientaçóes para o caminho ainda pela frente.

\section{RECONHECER A COMPLEXIDADE DE PERCORRER CAMINHO DES- CONHECIDO}

Para a educação, como atividade eminentemente comunicacional, a retenção, repentina e inesperada, das pessoas nas suas casas, impedidas de se encontrarem nos espaços e instituiçôes educativas, resultou numa situação difícil e complexa que gerou perplexidade e compreensíveis receios. Não abordando as questôes económicas, sociais e psicológicas, por serem áreas que outras especialidades também se encontram a estudar, no campo educativo rapidamente se identificaram deficits de equipamento informático e de condiçóes de acesso às redes de comunicação que poderiam, supletivamente, assegurar a comunicação entre alunos e professores. Retidas em casa, as famílias tiveram de se adaptar, alterando as rotinas e transformando-se em estaçôes de teletrabalho dos pais e em escolas com deficit de adultos especializados nas funçôes educativas indispensáveis à relação pedagógica. Todos tiveram de se adaptar a um novo contexto, de contornos desconhecidos, para além de ainda indefinidos.

Ao mesmo tempo, para as comunidades e, em especial, para os seus líderes, além da conceção e implementação urgente de soluções alternativas, colocou-se a prioridade de não deixar acentuar as desigualdades.

Em Portugal, sob o lema governamental "Não paramos. Estamos ON” foram tomadas medidas diversas, incluindo no setor educativo, para o qual foi providenciado um "conjunto de recursos para apoiar as escolas na utilização de metodologias de ensino a distância que lhes permit[issem] dar continuidade aos processos de ensino e aprendizagem” (DGE, 2020). E a Universidade do Minho, que, no Instituto de Educação, acolhe um Centro de Competência TIC (CCTIC), estruturas que, "em 
estreita colaboração com a ERTE (Equipa de Recursos e Tecnologias Educativas), têm como missão apoiar as escolas na integração curricular das TIC, contribuindo, desta forma, para o desenvolvimento das competências digitais na educação" (ERTE, 2020), foi imediatamente disponibilizado um serviço para "ajudar os professores a resolver alguns dos problemas mais imediatos relacionados com ensinar e aprender a distância” (CCTICIE-UM 2020); ainda neste Instituto, foram criados, de raiz, dois novos projetos: - o projeto “Trancadas em Casa!”, com o "intuito de acolher as vozes das crianças e divulgar as suas vivências e necessidades” (IEUM, 2020b);

- a Rede Aproximar, um “projeto de intervenção socioeducativa e comunitária com mediação tecnológica destinado à População Idosa em situação de isolamento social em Portugal, agravado em consequência da pandemia COVID-19” (IEUM, 2020a).

Reagindo proativamente, também outras instituiçôes educativas e grupos profissionais mais ou menos estruturados, desencadearam açóes diversas; a título ilustrativo, identificamos algumas dessas iniciativas:

- dois docentes da Faculdade de Educação e Psicologia da Universidade Católica Portuguesa, com a participação de quase três dezenas de professores, organizaram uma obra que retrata as peripécias do ensino e aprendizagem em tempo de COVID-19, identificando boas práticas e tendências para o futuro da educação (Alves \& Cabral, 2020);

- a Secção de Educação a Distância da Sociedade Portuguesa de Ciências da Educação, estimulou os académicos e especialistas em elearning a assumirem “a responsabilidade de partilharem a sua experiência com todos os colegas que agora se defrontam, pela primeira vez, com situaçóes reais de ensino-aprendizagem a distância" (SEAD-SPCE, 2020), proporcionando um conjunto de apontadores para testemunhos, experiências, recursos e serviços com utilidade diversificada; - o projeto \#somossolução (2020) "surgiu a partir de um grupo criado no Facebook E-Learning - apoio, [com a] intenção [de] ajudar profissionais da educação, a adaptarem-se à nova realidade fruto do encerramento das escolas”, agregando 30 milhares de professores. 
Sendo ainda muito prematuro fazerem-se balanços sobre o real contributo da tecnologia para a continuação da atividade educativa durante a pandemia, fará sentido registar a caracterização feita pelo proponente, em 1985, do Projeto MINERVA (introdução dos recursos informáticos na educação não superior em Portugal), e seu Coordenador nacional durante a fase piloto (outubro de 1985 a outubro de 1988): designando-o por "ensino remoto de emergência”, o Professor António Dias de Figueiredo, assinalou-o como uma forma de "manter as crianças funcionais para a aprendizagem e intelectualmente ativas durante os meses em que se sabia que não iriam à escola - um objetivo nobre, meritório e imensamente trabalhoso" (Figueiredo, 2020b).

Noutras geografias do planeta, também encontrámos formas diversificadas de reagir à nova conjuntura. A título ilustrativo dos projetos postos em curso, podemos referir o "CovEducation" que permitiu "combinar estudantes universitários com alunos mais jovens para facilitar a aprendizagem online" (Winn, 2020). Com a realidade pandémica a verificar-se à escala global, alguém interessado em conhecer experiências vividas noutras paragens, poderá consultar a base de dados de abordagens emergentes que o Banco Mundial está a catalogar (WorldBank, 2020).

Estas iniciativas, projetos, recursos e partilhas de experiências, proporcionando ajudas em diferentes componentes do processo educativo, evidenciam a capacidade de os intervenientes nesse processo se organizarem para proverem a necessidades em situações críticas emergentes. Uma síntese breve deste 'reconhecimento do terreno', desta constatação da realidade, tanto quanto é possível mapeá-la, permite-nos enunciar um leque de dimensões de análise da utilidade e potencial das tecnologias, ao serviço de fins educativos:

- estruturação e provimento de infraestrutura de equipamentos computacionais e de redes comunicacionais;

- identificação e difusão de ferramentas de aprendizagem amigáveis;

- disponibilização de repositórios e recursos digitais de aprendizagem qualificados e adequados;

- divulgação de métodos de ensino e de aprendizagem alternativos, ativos e inovadores; 
- criação e operacionalização de serviços de apoio para professores e alunos; - cooperação e colaboração entre escolas, instituições da comunidade, empresas, autarquias e serviços governamentais.

\section{REGISTAR AS DESCOBERTAS NO PERCURSO}

Como expressou o Professor Jorge Teixeira (2020), “o digital não é o fim, é o meio”. As tecnologias asseguram algumas das condiçốes necessárias para que o foco das aprendizagens possa "incidir sobre a criatividade, o "porquê das coisas" e o "para quê” do esforço em aprender” (Teixeira, 2020). Essa centralidade das aprendizagens, e da função das tecnologias nesse processo, é o foco desta parte do texto, estruturada para tentar explicitar algumas descobertas que afloram das experiências que temos vivido ou a que vimos assistindo.

\section{APRENDIZAGENS SOBRE A INFRAESTRUTURA DO ESPAÇO EDU- CATIVO}

Sendo a escola o espaço da educação, a envolvente onde se realiza a relação aluno-professor, o ambiente da interação educando-educador, percebemos que os estabelecimentos escolares que proporcionam pontos de encontro e presença física têm de ser complementados com infraestruturas computacionais e comunicacionais que proporcionem uma presença onlife (Floridi, 2015), já que vivemos numa era hiper conectada, em que as "nossas ações, perceções, intençôes, moralidade e até corporalidade estão entrelaçadas com tecnologias” (Floridi, 2015). A definição de soluçôes que satisfazem as infraestruturas necessárias ao encontro dos intervenientes no processo, tende a incluir opções flexíveis, modalidades híbridas, respostas a selecionar de um continuum que, num dos polos, pode ser exclusivamente presencial (físico, offine) e, no outro, totalmente digital (online).

Uma especulaçãoo (Osorio, 1997) do final do século passado pode ilustrar um cenário inteiramente viável no presente: "Através da exploração dos vários recursos de diferentes aplicaçôes telemáticas, adotando a ferramenta mais apropriada para cada necessidade identificada, uma combinação equilibrada de aplicativos telemáticos pode 
desenvolver um senso de presença 'virtual', que pode muito bem ser mais eficaz do que em situações de presença física. Uma seleção de aplicações telemáticas, intencional, cuidadosa e especializada, combinada de maneira abrangente, provavelmente fornecerá condiçóes para o desenvolvimento de ambientes/sistemas de aprendizagem ricos e compreensivos, onde o todo é mais do que, apenas, a soma das partes.”

Num tempo em que pode ser insensato ignorar que 25\% dos jovens portugueses que participaram no Dia da Defesa Nacional em 2019, afirmaram passar 6h diárias na Internet (Carapinha, Calado, \& Neto, 2020), compreende-se admitir e prever que as experiências de aprendizagem incluam vivências com utilização regular, intencional e consciente das tecnologias. Registe-se que há quem argumente que o acesso assegurado (gratuito) à Internet deve ser considerado e incluído no conjunto dos direitos humanos (Reglitz, 2020).

\section{APRENDIZAGENS SOBRE O QUE APRENDER E ENSINAR}

Assumindo que se vê o aluno como o centro do processo educativo, pensar e aprender a pensar, ganham cada vez mais relevância como objeto da atividade de aprender e ensinar. Esta visão "torna possível pensar na educação como uma entidade afetiva, por direito próprio, ou seja, uma entidade que não serve um propósito preexistente, mas traz consigo o propósito que serve” (Osberg \& Biesta, 2020). É uma visão que ajuda a operacionalizar uma escola para aprender a pensar (Almeida, 2002), uma escola onde os alunos dispóem das condiçôes que proporcionam o pensar criativamente, o raciocinar sistematicamente e o trabalhar colaborativamente (Resnick, 2017).

Como problemática transdisciplinar, o potencial educacional das tecnologias, cuja experimentação ganhou amplitude face à conjuntura pandémica, torna-se também um catalisador de pesquisas e aprendizagens interdisciplinares e, até, também transdisciplinares. É que o ensino a distância de emergência induz a necessidade de relativizar os currículos e programas padronizados, através da abordagem de temáticas mais abertas, recorrendo a metodologias diversificadas, interativas e colaborativas que, quando conseguidas, são valorizadas. Partilhar práticas vividas, conceber narrativas ilustrativas dessas vivências e comunicar experiências reflexivas, são possibilidades 
educativas a assinalar. Esta possibilidade pode ser ilustrada por uma experiência descrita num site educativo americano (Edutopia, 2020): "à medida que o mundo se fechava, a imaginação de estudantes e professores em todo o país foi capturada num trabalho de fotografia do ensino secundário.” Experiências anteriores (Valente, Osório, \& Dias, 2008) permitem imaginar a mais-valia qualitativa deste tipo de realizações educativas distribuídas.

\section{APRENDIZAGENS SOBRE COORDENAÇÃO E LIDERANÇA}

Ao percorrer caminho desconhecido, as lideranças precisam de poder assumir responsabilidades, sem grandes possibilidades, no momento de tomar decisões, de se referenciarem a estruturas de coordenação e governança. Esta dimensão ganha especial relevância quando se podem percorrer vários caminhos, quando se podem proporcionar soluçóes diversas e flexíveis para problemas e ocorrências diferentes e diversificadas. Numa navegação à vista, a abertura para observar o ambiente e incorporar dados que permitam uma visão ecológica do processo, são sugestôes que regularmente vêm sendo propostas.

Soluçôes de geometria variável (Figueiredo, 2020a) em que haja recurso a aprendizagem combinada (Figueiredo, 2020b) parecem consensuais. São soluçôes que permitem "favorecer a autonomia do aluno no uso seletivo das estratégias, de acordo com as suas características pessoais e as exigências das situações” (Almeida, 2002), bem como tirar partido do conhecimento disponível sobre colaboração em ambientes virtuais - ver, por exemplo, Miranda-Pinto \& Osório (2010) ou Meirinhos \& Osório (2014).

A viabilização dessas opções, que existem disponíveis e se encontram validadas, requerem dos intervenientes no processo educativo com funções e responsabilidades de coordenação e liderança, capacidade de proporcionar a autonomia sugerida por (Figueiredo, 2020c): "a primeira evidência que este período de pandemia revelou [...] foi, assim, a da necessidade de uma autonomia inteiramente nova para as escolas”.

Essa clarividência será indispensável para gerir a disponibilidade evidenciada num inquérito a cerca de quatro mil docentes, coordenado pelo Professor João Marôco, 
onde fica expresso que a experiência de ensino a distância suscitou uma mudança de atitude face à utilização de recursos digitais: "o inquérito dá conta que, após a pandemia e caso tenham oportunidade para tal, $91 \%$ dos inquiridos pretendem desenvolver atividades em sala de aula com software e aplicativos digitais educacionais" e que $80 \%$ também pensam usar "avaliação formativa online" (Viana, 2020). Com o fecho das escolas, os professores tiveram de ser criativos e, com isso, parece terem aprendido coisas que vão querer usar ao voltar à escola; noutras paragens, refere uma professora (Cooper, 2020): "pretendo incorporar essa [estratégia] por voz ou na tela, ou ambos, quando nos voltarmos a encontrar na vida real”.

\section{PERSPETIVAR NOVOS CAMINHOS E, EM CONSEQUENCIA, NOVOS MUNDOS}

Ainda no início da crise pandémica, com humor, alguém sugeriu que se reinstalasse o ano de 2020, em virtude de a atual versão ter sido infetada com um vírus. A realidade, contudo, é algo mais séria e sugere-nos que apenas podemos estar certos da incerteza. Ainda assim, com base em apreciaçôes e reflexóes que vêm sendo partilhadas, é possível identificarmos linhas de orientação que permitem perspetivar como lidar com novos caminhos que se nos podem deparar. Vale a pena acolher a sugestão de jovens refletindo sobre a crise ambiental, quando constatam que, com a crise pandémica, "o mundo mostrou capacidade de se unir e de lutar por um objetivo comum, [assinalando que] agir pelo meio ambiente exige essa unidade mundial" (Calderón, Ramirez, Hossain, \& Mahachi, 2020). Pode ser considerado ingénuo, mas ajuda a que haja esperança no futuro... Arriscando insistir na ingenuidade, a essa luz poderá ser acolhido o investimento governamental português em recursos digitais para a infraestrutura tecnológica do sistema educativo, anunciado publicamente em junho de 2020.

A par com esperanças entusiastas, é também sensato acautelar o possível excesso e desregulação de trabalho e de horários que pode advir com o digital e suas plataformas, problemática para a qual sindicatos e associações profissionais vão alertando. Académico insuscetível de ser considerado opositor das tecnologias, "questionando, desafiando e criticando como a tecnologia digital está a moldar o nosso trabalho como académicos da universidade contemporânea”, Selwyn (2016) previne 
"podermos estar com um grande problema se a tecnologia digital for considerada um modelo para a futura [educação]”.

Assim prevenidos, ponderemos "uma pesquisa realizada com 1500 pessoas [evidenciando] que muitos pais que trabalham, percebem que grande parte da sua atividade pode ser realizada remotamente [e] acreditam que os seus empregadores concordarão" (Doward, 2020). Admitindo que a diversidade de formatos educativos se divulgará, podemos vir a assistir a opçóes educativas que tirem partido de diferentes organizações de tempo e de diversificadas escolhas de localizações geográficas. Vejamos dois exemplos elucidativos:

- ficou demonstrado que, conjugados com sistemas de teletrabalho, pode haver sistemas de educação a distância, economizando-se tempo e energia despendidos nas movimentações casa-escola-trabalho-escola-casa; com isso, surge mais plausível a possibilidade de avançarem os estudos com vista a formatos de trabalho com, por exemplo, semanas de 4 dias;

- combinando regimes de ensino doméstico com sistemas de ensino mediatizado do tipo do \#EstudoEmCasa em Portugal, sabendo que entre os seus $95 \mathrm{mil}$ espetadores, mais de 1/3 tinha mais de 35 anos e que vários milhares assistiram a aulas fora do país (Tulha, 2020), fácil fica imaginar mais famílias em viagens pelo mundo ou instaladas em geografias interiores, remotas ou isoladas.

Estas vivências e possibilidades salientam a importância de as instituiçốes de ensino construírem vínculos mais estreitos entre as experiências de aprendizagem dos alunos dentro e fora da escola e de "desenvolverem iniciativas que promovam a aquisição das habilidades digitais necessárias para maximizar o potencial de aprendizagem de novos contextos de atividade" (Engel, Coll, Membrive, \& Oller, 2018).

Sucede que é muito elevado o nível de sofisticação das TIC atualmente acessíveis quase ubiquamente. Recorrendo a mais um exemplo, Scarlet, um assistente digital pessoal capaz de "dar uma resposta adequada a uma pergunta específica com base em conhecimento recolhido por um algoritmo exclusivo, que lhe permite reconhecer o contexto numa pesquisa na web” (Ilhan, Mušić, Junuz, \& Mirza, 2017), lembra-nos que a inteligência artificial estará cada vez mais presente no nosso quotidiano. Não 
sabemos ao certo o que será o futuro, nem poderemos vir a verificar a concretização do cenário apresentado por Beard (2020), mas sabemos que há quem preveja que "o futuro consistirá no emparelhamento da inteligência artificial dos computadores com as capacidades cognitivas, sociais e emocionais dos seres humanos, para que eduquemos humanos de primeira classe, não robôs de segunda classe” (Schleicher et al., 2019).

\section{SÍNTESE}

Começámos por salientar a importância de melhor conhecer como controlar a tecnologia e fomos desenvolvendo um raciocínio em torno das aprendizagens obtidas sobre a função da tecnologia na educação, ao longo da vivência da crise pandémica. Podendo o confinamento ter de se prolongar mais ou menos intensamente, sabemos que a educação não tem de parar, pois dispomos da tecnologia que suporta várias modalidades de funcionamento adequado do processo educativo. Além de dispormos de opçốes diversas, sabemos da flexibilidade de modelos já testados e que, com ferramentas de inteligência artificial, “o futuro da aprendizagem será uma experiência personalizável, adaptada às singularidades de cada um” (Monteiro, 2019).

Convivendo com as restriçốes impostas pela COVID-19, pudemos constatar, por outro lado, a dependência que temos e a relevância das famílias, dos educadores e dos professores, para que ocorra o processo educativo de todos, ao logo de todas as faixas etárias. E também ficámos cientes que a boa qualidade do processo educativo é a que integra equilibradamente, os diferentes intervenientes, nos diversos momentos da vida, em todos os possíveis locais e percursos, para alcançar as mais diversas finalidades, algumas delas desconhecidas.

Aqui chegados, após ter refletido sobre a relação da tecnologia com a educação em tempo de pandemia, talvez possamos afirmar que estamos em melhores condiçóes para, com mais confiança, encararmos novos desafios que o futuro, com certeza, nos vai propor. 


\section{REFERÊNCIAS BIBLIOGRÁFICAS}

\#somossolução (2020). Soluçôes em eLearning. Consultada a 2020/06/30 em https://somossolucao.com/.

Alves, J. M., \& Cabral, I. (Eds.). (2020). Ensinar e aprender em tempo de COVID-19: entre o caos e a redenção. Porto: Faculdade de Educação e Psicologia da Universidade Católica Portuguesa.

Calderón, G. B., Ramirez, J. O., Hossain, K. Z., \& Mahachi, T. T. (2020). Environmental Crisis: What we learned from COVID-19. Consultada a 2020/06/30 em https://www.scout.org/youth-environmental-action ?fbclid=IwAR3DKARS 7aieElfjEUHd7jDZxg55d9qsKgkG01EbuJrZfKuwIBfblvM6lo.

Carapinha, L., Calado, V., \& Neto, H. (2020). Comportamentos Aditivos aos 18 anos. Inquérito aos jovens participantes no Dia da Defesa Nacional - 2019. Consultada a 2020/06/30 em http://www.sicad.pt/ BK/EstatisticaInvestigacao/EstudosConcluidos/Lists/SICAD_ESTUDOS/Attachments/208/DDN2019 InqCAD RelatorioNacional.pdf.

CCTICIEUM (2020). Apoio online a Professores. Consultada a 2020/06/30 em https://www.nonio.uminho. pt/?page id $=31$.

Cooper, S. (2020). Distance Learning Strategies to Bring Back to the Classroom. Consultada a 2020/06/30 em https://www.edutopia.org/article/distance-learning-strategies-bring-back-classroom.

DGE (2020). Apoio às Escolas. Consultada a 2020/06/30 em https://apoioescolas.dge.mec.pt/node/391.

Doward, J. (2020). Only $13 \%$ of UK working parents want to go back to 'the old normal'. The Guardian. Consultada a 2020/06/30 em https://www.theguardian.com/world/2020/jun/28/only-13-of-uk-workingparents-want-to-go-back-to-the-old-normal? CMP=Share_iOSApp_Other\&fbclid=IwAR1GTkxshV g4mcFAMYAmOfiDa2LdgpOZgqmGFi9E6OW3JxQWcrzV_O16ZA.

Edutopia (2020). Student Photographers Document History During the Pandemic. Consultada a 2020/06/30 em https://www.edutopia.org/video/student-photographers-document-history-during-pandemic.

Engel, A., Coll, C., Membrive, A., \& Oller, J. (2018). Information and communication technologies and students' out of-school learning experiences. Digital Education Review, 130-149.

ERTE (2020). Centros de Competência TIC. Consultada a 2020/06/30 em https://www.erte.dge.mec.pt/ centros-de-competencia-tic.

Figueiredo, A. D. (2020a). E Depois do Ensino Remoto de Emergência? Ponto da Situação e Próximos Desafios. Consultada a 2020/06/30 em http://adfig.com/pt/?p=585.

Figueiredo, A. D. (2020b). Os Equivocos da Educação à Distância. Consultada a 2020/06/30 em https:// www.sinalaberto.pt/os-equivocos-da-educacao-a-distancia/?fbclid=IwAR030FdXDcUGFATcd0Zrg7l2ar$\underline{\operatorname{lmR} v j R l k u I 1 h 8 \text { etpenCAJyxcDBClO9EA. }}$

Figueiredo, A. D. (2020c). Que Educą̧ão para a Era Pós-COVID-19? Consultada a 2020/06/30 em http:// adfig.com/pt/?p=541. 
Floridi, L. (2015). Introduction. In L. Floridi (Ed.), The Onlife Manifesto: Being Human in a Hyperconnected Era (pp. 1-3). Cham: Springer International Publishing.

Hardoon, D., \& Barnaby, E. (Producer). (2020). Learning (Episode 3 of 3). Consultada a 2020/06/30 em https://www.bbc.co.uk/sounds/play/m000hq1m.

IEUM (2020a). Rede Aproximar. Consultada a 2020/06/30 em https://www.facebook.com/projeto.rede. aproximar/.

IEUM (2020b). Trancadas em casa - As crianças fintam a COVID-19!. Consultada a 2020/06/30 em https:// www.trancadasemcasa.pt/sobre-nos/.

Ilhan, K., Mušić, D., Junuz, E., \& Mirza, S. (2017). Scarlet - Artificial Teaching Assistant. Paper presented at the 2017 International Conference on Control, Artificial Intelligence, Robotics \& Optimization (ICCAIRO).

Meirinhos, M., \& Osório, A. (2014). A Colaboração em Ambientes Virtuais: aprender e formar no século XXI. Braga: ArcaComum.

Miranda-Pinto, M., \& Osório, A. J. (2010). Dinâmicas, colaboração e liderança na @rcaComum. In A. J. Osório \& M. Miranda-Pinto (Eds.), Infância no digital (pp. 155-171). Braga: ArcaComum.

Osberg, D., \& Biesta, G. (2020). Beyond curriculum: Groundwork for a non-instrumental theory of education. Educational Philosophy and Theory, 1-14.

Osorio, A. J. (1997). Telematics for the education and professional development of teachers. Doctoral Thesis. University of Exeter School of Education.

Osório, A. J. (2020, 24/4/2020). Tecnologia educativa em tempo de pandemia - reflexões soltas, mas pensadas. Público.

Reglitz, M. (2020). The Human Right to Free Internet Access. Journal of Applied Philosophy, 37(2), 314-331. Resnick, M. (2017). Lifelong Kindergarten: Cultivating Creativity Through Projects, Passion, Peers, and Play: MIT Press.

Rutter, M. (2020). Rolling out remote learning. Consultada a 2020/06/30 em http://news.mit.edu/2020/ rolling-out-remote-learning-0330?fbclid=IwAR2DCL7SJJeWRO5cwPMFVWk7phMYg2xICcONvrse51u zpvZsCaAuVQELsOk.

Schleicher, A., Achiron, M., Burns, T., Davis, C., Tessier, R., \& Chambers, N. (2019). Envisioning the Future of Education and Jobs: Trends, Data and Drawings. Consultada a 2020/06/30 em http://www.oecd.org/ education/Envisioning-the-future-of-education-and-jobs.pdf.

SEAD-SPCE. (2020). COVID-19 A DISTANNCIA. Consultada a 2020/06/30 em https://sead.spce.org.pt/.

Selwyn, N. (2016). Academic work in the digital age. Consultada a 2020/06/30 em http://der.monash.edu.au/ $\underline{\operatorname{lnm} / \text { academic-work-in-the-digital-age-recording-transcript-of-talk-by-neil-selwyn/. }}$ 
Spector, J. M. (2020). Remarks on progress in educational technology. Educational Technology Research and Development, 68(3), 833-836.

Teixeira, J. (2020). A pandemia do digital na educação. Consultada a 2020/06/30 em https://observador.pt/ opiniao/a-pandemia-do-digital-na-educacao/.

Tulha, A. (2020, 28/6/2020). Aprender ao sabor da maré. Notícias Magazine.

Valente, A. L., Osório, A. J., \& Dias, P. (2008). Pintura digital online: cursos e recursos para crianças e adultos. In P. Dias \& A. J. Osório (Eds.), Ambientes Educativos Emergentes (pp. 143-157). Braga: Centro de Competência da U. Minho.

Viana, C. (2020,26/6/2020). Professores querem levar o mundo digital também para as salas de aulas. Público.

Consultada a 2020/06/30 em http://www.publico.pt/2020/06/26/sociedade/noticia/professores-queremlevar-mundo-digital-tambem-salas-aulas-1922131.

Winn, Z. (2020). Helping K-12 students overcome school closures. Consultada a 2020/06/30 em http://news. mit.edu/2020/coveducation-students-school-closures-0417.

WorldBank. (2020). How countries are using edtech (including online learning, radio, television, texting) to support access to remote learning during the COVID-19 pandemic. Consultada a 2020/06/30 em https://www. worldbank.org/en/topic/edutech/brief/how-countries-are-using-edtech-to-support-remote-learning-duringthe-COVID-19-pandemic. 